\title{
Dehiscence of cesarean section scar during pregnancy and delivery - risk factors
}

\author{
Marwan Odeh ${ }^{1,2} \oplus$, Rawan Karwani², Oleg Schnaider ${ }^{1,2}$, \\ Maya Wolf1, 2D, Jacob Bornstein 1, 2D \\ ${ }^{1}$ Galilee Medical Center, Nahariya, Israel \\ ${ }^{2}$ Azrieli Faculty of Medicine, Bar Ilan University, Safed, Israel
}

\begin{abstract}
Objective: We wanted to identify risk factors for dehiscence of cesarean section (CS) scars in patients undergoing repeated cesarean section.

Material and methods: This was a retrospective case-control study over a 3-year period in our medical center (2011-2014), comparing women who had repeated CS without complications and women diagnosed with dehiscence. Data were collected from medical records and the groups were compared for demographic and obstetrical data.

Results: Dehiscence was identified in 27 women, while 54 women without dehiscence were the control group. Statistically significant differences were found in the need for augmentation, the number of previous cesarean sections, cesarean section in the active phase of labor and length of hospitalization.

Discussion: The need for augmentation of labor, CS in the nonactive stage and more than one cesarean section, all increased the risk of dehiscence. There was no association between dehiscence and scar pain, time elapsed since the previous cesarean section, the method of wound closure or fever.
\end{abstract}

Key words: cesarean scar dehiscence; augmentation of labor; active phase of labor; scar pain; cesarean section

Ginekologia Polska 2020; 91, 9: 539-543

\section{INTRODUCTION}

Uterine rupture refers to complete disruption of all uterine layers, including the serosa. It is a life-threatening pregnancy complication for both mother and fetus in women undergoing a trial of labor after cesarean section (TOLAC). Other adverse outcomes include complications relating to severe hemorrhage, bladder laceration, hysterectomy, and neonatal morbidity relating to intrauterine hypoxia. Most uterine ruptures in resource-rich countries are associated with TOLAC. In resource-limited countries, many uterine ruptures are due to obstructed labor and lack of access to operative delivery. By comparison, uterine dehiscence generally refers to an incomplete, and frequently clinically occult, uterine scar separation where the serosa remains intact and is not usually associated with hemorrhage or adverse maternal or perinatal outcomes. It is found incidentally in $<2 \%$ of prior Caesarean section patients [1]. Madaan et al. [2] (2011) found four cases of uterine rupture out of 300 patients undergoing TOLAC 3 diagnosed during laparotomy for suspected rupture and one case due to severe post-partum hemorrhage. In the same study, six cases of dehiscence were diagnosed, all during repeated cesarean [2]. A study of 188 women attempting vaginal birth after cesarean section (VBAC) found that previous vaginal delivery and non-recurrent indication for the previous cesarean section were good predictors of successful VBAC [3]. This study also found that uterine rupture/dehiscence was $6.5 \%$ and $4.8 \%$ in recurrent and non-recurrent indication, respectively [3].

Most cases of uterine dehiscence are diagnosed incidentally at repeat cesarean delivery, but some are identified during a prenatal ultrasound examination, sometimes with extrusion of a sac containing fetal membranes and amniotic fluid. A defect in the scar may detected as early as the first trimester, with the possibility of "cesarean scar" pregnancy [4]. Scar defects and uterine windows have also been detected in the non-pregnant uterus $[5,6]$.

The management of dehiscence during pregnancy is influenced by gestational age (e.g. previable, preterm viable, term), but there is insufficient evidence to make firm recommendations. Near term, repeat cesarean delivery before the onset of labor is probably the safest option to avoid 
progression to rupture. Remote from term, published and anecdotal case reports have described successful outcomes with expectant management, close monitoring, and early delivery [7, 8] and with laparotomy to repair the defect [9]. However, there is no standard or optimal approach: if the pregnancy is continued, the patient should be thoroughly counseled about the potential risks to her and to the fetus.

A large study by Miller et al (1994) of more than 1000 women who had a trial of labor after cesarean (TOLAC) found that the uterine rupture rate was $1.7 \%$ in women who had had two or more cesarean sections vs $0.6 \%$ in women who had had one caesarean section [10]. A smaller study by Caughey et al. [11] (1999) of 134 women found that 3.7\% of women who had had two cesarean sections experienced uterine rupture compared with $0.8 \%$ of women who had had one cesarean section.

A retrospective study of signs, symptoms, and complications of partial and complete uterine rupture done between 1987-2008 revealed that $18.5 \%$ of the women who had partial rupture complained about abdominal pain vs $32 \%$ of the women who had complete rupture, without statistical significance [12]. In another study, only 5\% of women who did not receive epidural anesthesia and had a rupture in the uterus experienced scar pain [13], while Johnson et al. [14] (1990), conducted a study of 10.976 women who underwent TOLAC, where only $22 \%$ of the women who had uterine rupture had complained of abdominal pain.

\section{Objectives}

The purpose of our study was to identify risk factors for scar dehiscence, in order to suggest management of repeat cesarean section and careful evaluation of the cesarean scar.

\section{MATERIAL AND METHODS}

This study was approved by the Institutional Review Board (Helsinki Committee) of our medical center. The electronic medical records between 1.1.2011 and 7.7.2014 in our center were retrospectively searched using the terms "dehiscence of scar" or "rupture of the uterus" or "uterine scar".

The control group was selected from women with a repeat cesarean section without evidence of scar dehiscence at the same time period as the women in the study group. For each woman in the study group we matched two women for the control group who delivered by cesarean section immediately after the woman in the study group. If two consecutive women were diagnosed with dehiscence, then four consecutive women were chosen for the control group. All women were healthy and had not undergone any surgery on the uterus after the first cesarean section which may have affected the structure of the uterus.

The following parameters were included in the data collection: age, number of pregnancies, number of births, spontaneous abortions, termination of pregnancy, ectopic pregnancy, number of cesarean sections, number of births after the first cesarean section, the number of pregnancies with dehiscence, cause of first and last cesarean section, complaints about pain in the surgical scar, evidence of infection or fever after the last cesarean section (fever was determined by two temperature measurements above 38 with a range of 6 hours). We also examined whether there was evidence of infection during surgery (according to the surgical report), duration of hospitalization at previous birth, uterine incision closing method in the previous cesarean section (either one or two layers), time elapsed between last birth and present (< or > 18 months), need for and type of augmentation of labor, type of anesthesia and the stage of labor when the cesarean was performed.

\section{Statistical analysis}

Quantitative data were described using mean and standard deviation/median and range according to data distribution. Quality data were described using prevalence and percentage. For comparison between the research group and the control group, quantitative data were evaluated using the Wilcoxon rank sum test due to their asymmetric distribution. The age of the women was examined using an independent sample t-test. Qualitative data were examined using Chi-square test or Fisher's exact test.

\section{RESULTS}

The study group consisted of 27 women diagnosed with dehiscence, while the control group consisted of 54 women. All women had at least one cesarean section.

There was no statistically significant differences between the study group and the control group in age, number of births or pregnancies, number of abortions or termination of pregnancy (TOP), ectopic pregnancy, and number of births after the first cesarean section (Tab. 1). Women in the study

\begin{tabular}{|l|l|l|l|}
\hline \multicolumn{4}{|l|}{ Table 1. Demographic data for each group } \\
\hline Parameter & Case & Control & p \\
\hline $\begin{array}{l}\text { Age (mean } \pm \text { standard } \\
\text { deviation) }\end{array}$ & $30.1( \pm 5.4)$ & $30.1( \pm 5.3)$ & NS \\
\hline $\begin{array}{l}\text { Number of pregnancies } \\
\text { (median and range) }\end{array}$ & $3(2-6)$ & $3(2-11)$ & NS \\
\hline $\begin{array}{l}\text { Number of births } \\
\text { (median and range) }\end{array}$ & $2(1-4)$ & $2(1-9)$ & NS \\
\hline \begin{tabular}{l} 
Spontaneous abortions \\
\hline TOP
\end{tabular} & 11 & 14 & NS \\
\hline $\begin{array}{l}\text { Ectopic pregnancy } \\
\text { Number of births after first } \\
\text { cesarean section (2 or more) }\end{array}$ & 3 & 8 & NS \\
\hline
\end{tabular}

NS - not significant 


\begin{tabular}{l|l|l|l|}
\hline \multicolumn{3}{|l|}{ Table 2. Number of cesarean sections in both groups } \\
\hline $\begin{array}{l}\text { Number of cesarean } \\
\text { sections }\end{array}$ & Control & Case & p \\
\hline One CS & $77.80 \%$ & $55.60 \%$ & NS \\
\hline Two CSs & $22.20 \%$ & $37.00 \%$ & 0.034 \\
\hline Three or more CSs & $0 \%$ & $7.40 \%$ & \\
\hline
\end{tabular}

NS - not significant; CS - cesarean section

Table 3. Comparison between the two groups

\begin{tabular}{|c|c|c|c|}
\hline Parameter & Control & Case & p \\
\hline $\begin{array}{l}\text { Time elapsed from previous } \\
\text { cesarean section less } \\
\text { than } 18 \text { months }\end{array}$ & $14.80 \%$ & $18.50 \%$ & NS \\
\hline $\begin{array}{l}\text { Cervical opening in } \\
\text { previous cesarean section } \\
\text { (active stage of labor) }\end{array}$ & $44.40 \%$ & $18.50 \%$ & 0.027 \\
\hline Augmentation & $1.90 \%$ & $22.20 \%$ & 0.005 \\
\hline \multirow{3}{*}{$\begin{array}{l}\text { Spinal anesthesia } \\
\text { Epidural anesthesia } \\
\text { General anesthesia }\end{array}$} & $85.20 \%$ & $77.80 \%$ & NS \\
\hline & $9.30 \%$ & $11.10 \%$ & \\
\hline & $5.60 \%$ & $11.10 \%$ & \\
\hline $\begin{array}{l}\text { Closing uterine incision by } \\
\text { one layer }\end{array}$ & $79.20 \%$ & $80.80 \%$ & NS \\
\hline Scar pain & $14.80 \%$ & $18.50 \%$ & NS \\
\hline Fever & $5.70 \%$ & $4 \%$ & NS \\
\hline
\end{tabular}

NS - not significant

group had a higher number of cesarean sections than women in the control group with statistical significance (Tab. 2).

Table 3 summarizes the comparison between the two groups: there were statistically significant differences between the groups in the need for augmentation (more in the study group) and the stage of labor when the last cesarean was performed (more active stage in the control group) while other parameters were not statistically different. In both groups, the most common anesthesia type was spinal anesthesia, $82.7 \%$ compared to epidural and general. $34.6 \%$ of the women in the study group were hospitalized for more than 5 days compared to $13.0 \%$ of the control group. Statistically significant difference $p=0.036$ (Fisher's Exact Test).

\section{DISCUSSION}

The main purpose of this study was to identify factors that increase the risk of dehiscence to avoid or reduce the risk of this life-threatening complication in future pregnancy.

The study results showed that women in the study group had a higher number of cesarean sections. Many studies have shown that women undergoing cesarean section are at increased risk of maternal and fetal complications later $[10,11,15-17]$. Our results agree with other studies since repeated CS creates yet another scar that further weakens the lower segment of the uterus, thus increasing the risk of dehiscence.

In $22.2 \%$ of women in the study group, compared with $1.9 \%$ of the control group, augmentation of labor was required with a statistically significant difference. Overall, seven women from both groups needed augmentation by nipple stimulation. In our department, it is not customary to implement pharmacological augmentation with oxytocin in women who have undergone a cesarean section in the past. Nipple stimulation increased the risk of dehiscence. The reason for this seems to be related to increased uterine contractions due to oxytocin release, but it is also possible that the need for the augmentation itself was due to the inability of the uterus to contract due to early dehiscence. Since our study is retrospective, it is not possible to determine what occurred first. A retrospective research study found that stimulation of the nipples in women with previous births and previous caesarean section is a safe and effective method [18]. In our study, augmentation increased the risk of dehiscence, thus evaluation of the scar is mandatory before any type of augmentation is implemented, and close surveillance is crucial if augmentation is given. The issue of labor induction in previous cesarean section is controversial, as was found in the survey conducted by Udayasankar et al. [19] (2008) among obstetricians in Wales. Although most obstetricians would consider induction of labor in postdate even in the event of previous cesarean section, about $88 \%$ of the obstetricians stated that these women should be counseled regarding the increased risk of uterine rupture.

There was no statistically significant difference between the study group and the control group concerning complaints of pain in the surgical scar, $18.5 \%$ of the women in the study group reported scar pain vs $14.8 \%$ in the control group. This result is also in agreement with previous studies [12-14]. Madaan et al. [2] (2011) concluded that scar tenderness and pain are poor indicators of scar dehiscence: in their series, 10 women were operated due to scar tenderness and dehiscence was not found in any of them.

There was no statistically significant difference between the closing methods of uterine incisions in previous cesarean section (either one or two layers). In our study uterine-incision closure by one layer was the most common method in the two groups. In a retrospective study of 292 women who underwent TOLAC, there was no difference in the percentage of uterine rupture comparing the two closure methods [20]. However, a large cohort study of 3.000 women showed a 4-fold chance of uterine rupture in the one layer vs two-layer closing method [21]. Our results support the first study that shows that the one-layer closure method does not increase the risk of scar rupture, however, a large randomized prospective study is needed to clarify this issue. 
We examined the medical records for fever in the previous CS since fever might indicate an infection of the scar, and subsequent impairment of the healing ability of the scar, thereby increasing the chance for dehiscence. However, the results of our study showed no difference between the two groups. One woman from the study group suffered from fever vs three women from the control group, $34.6 \%$ of the study group vs $13 \%$ of the control group were hospitalized for more than five days (statistically significant), and most hospital stays were for six days ( 12 women from both groups). One woman from the study group was hospitalized for 18 days due to septic shock, while two women in the control group were hospitalized more than five days suffering from fever. The other reasons for long hospitalization were not related to fever but to other causes such as proteinuria, shortness of breath, suspected pulmonary embolism and back pain.

In the control group, $44.4 \%$ were in their active stage of labor during the previous cesarean section compared to $18.5 \%$ of the study group, with statistical significance. We attribute this difference to the fact that in women operated during active stage, the lower segment is already formed and the incision in these cases is done mostly without cutting the uterus muscle itself. In women not in active labor, the incision is often done in the muscle itself, even if performed in the lower segment. This hypothesis should also be confirmed in a prospective study with histological proof of the lower segment composition during elective cesarean section vs cesarean section in women in active labor. Irrespective of the reason for this finding, it is particularly important to clarify at what stage of labor the CS was performed in each patient choosing TOLAC.

The weakness of this study, in addition to its being a retrospective analysis, is that some women with dehiscence of scar were not diagnosed because our study included only women with definitive diagnosis of dehiscence during a repeated cesarean. Women with asymptomatic dehiscence were probably discharged undiagnosed.

In conclusion, the need for augmentation of labor (breast stimulation), cesarean section on nonactive stage of labor and more than one cesarean section in the past are parameters that can increase the risk of dehiscence. There was no association between dehiscence and scar pain, time elapsed since the previous cesarean section, method of closure of the scar or fever. It is important to evaluate the scar's status in women with risk factors and especially if they choose a trial of labor.

\section{Conflict of interest}

All authors declare no conflict of interest.

\section{Compliance with ethical standards}

This study was approved by our Medical Center's Institution Review Board (Helsinki committee). It was not necessary to obtain informed consent due to the retrospective nature of the study.

\section{Funding}

This study was not funded by any outside sources.

\section{REFERENCES}

1. Landon MB. Predicting uterine rupture in women undergoing trial of labor after prior cesarean delivery. Semin Perinatol. 2010; 34(4): 267-271, doi: 10.1053/j.semperi.2010.03.005, indexed in Pubmed: 20654777.

2. Madaan M, Agrawal S, Nigam A, et al. Trial of labour after previous caesarean section: the predictive factors affecting outcome. J Obstet Gynaecol. 2011; 31(3): 224-228, doi: 10.3109/01443615.2010.544426, indexed in Pubmed: 21417645 .

3. Olagbuji B, Ezeanochie M, Okonofua F. Predictors of successful vaginal delivery after previous caesarean section in a Nigerian tertiary hospital. J Obstet Gynaecol. 2010; 30(6): 582-585, doi: 10.3109/01443615.2010.486085, indexed in Pubmed: 20701507.

4. Sadeghi H, Rutherford T, Rackow BW, et al. Cesarean scar ectopic pregnancy: case series and review of the literature. Am J Perinatol. 2010;27(2): 111-120, doi: 10.1055/s-0029-1224874, indexed in Pubmed: 19504427.

5. Osser OV, Jokubkiene L, Valentin L. High prevalence of defects in Cesarean section scars at transvaginal ultrasound examination. Ultrasound Obstet Gynecol. 2009; 34(1): 90-97, doi: 10.1002/uog.6395, indexed in Pubmed: 19499514.

6. Osser OV, Jokubkiene L, Valentin L. Cesarean section scar defects: agreement between transvaginal sonographic findings with and without saline contrast enhancement. Ultrasound Obstet Gynecol. 2010; 35(1): 75-83, doi: 10.1002/uog.7496, indexed in Pubmed: 20034000.

7. Hamar BD, Levine D, Katz NL, et al. Expectant management of uterine dehiscence in the second trimester of pregnancy. Obstet Gynecol. 2003; 102(5 Pt 2): 1139-1142, doi: 10.1016/s0029-7844(03)00162-5, indexed in Pubmed: 14607034.

8. Fox NS, Gerber RS, Mourad M, et al. Pregnancy outcomes in patients with prior uterine rupture or dehiscence. Obstet Gynecol. 2014; 123(4): 785-789, doi: 10.1097/AOG.0000000000000181, indexed in Pubmed: 24785605.

9. Matsunaga JS, Daly CB, Bochner $\mathrm{CJ}$, et al. Repair of uterine dehiscence with continuation of pregnancy. Obstet Gynecol. 2004; 104(5 Pt 2): 1211-1212, doi: 10.1097/01.AOG.0000142696.84491.ae, indexed in Pubmed: 15516456

10. Miller DA, Diaz FG, Paul RH. Vaginal birth after cesarean: a 10-year experience. Obstet Gynecol. 1994; 84(2): 255-258, indexed in Pubmed: 8041542.

11. Shipp TD, Zelop C, Repke JT, et al. Rate of uterine rupture during a trial of labor in women with one or two prior cesarean deliveries. Am J Obstet Gynecol. 1999; 181(4): 872-876, doi: 10.1016/s0002-9378(99)70317-0, indexed in Pubmed: 10521745.

12. Guiliano $M$, Closset $E$, Therby $D$, et al. Signs, symptoms and complications of complete and partial uterine ruptures during pregnancy and delivery. Eur J Obstet Gynecol Reprod Biol. 2014; 179: 130-134, doi: 10.1016/j. ejogrb.2014.05.004, indexed in Pubmed: 24965993.

13. Bujold $\mathrm{E}$, Mehta $\mathrm{SH}$, Bujold $\mathrm{C}$, et al. Interdelivery interval and uterine rupture. Am J Obstet Gynecol. 2002; 187(5): 1199-1202, doi: 10.1067/mob.2002.127138, indexed in Pubmed: 12439503.

14. Johnson C, Oriol N. The role of epidural anesthesia in trial of labor. Reg Anesth. 1990; 15(6): 304-308, indexed in Pubmed: 2291886.

15. Cunningham FG. et al.. Cesarean delivery and peripartum hysterectomy. In: Cunningham FG, Leveno KJ, Bloom SL. et al. ed. Williams Obstetrics. McGraw-Hill Education, New York 2010: 544-564.

16. Kolås $T$, Saugstad $O D$, Daltveit $A K$, et al. Planned cesarean versus planned vaginal delivery at term: comparison of newborn infant outcomes. Am J Obstet Gynecol. 2006; 195(6): 1538-1543, doi: 10.1016/j. ajog.2006.05.005, indexed in Pubmed: 16846577.

17. Tita ATN, Tita ATN, Lai Y, et al. Eunice Kennedy Shriver National Institute of Child Health and Human Development Maternal-Fetal 
Medicine Units Network, Eunice Kennedy Shriver National Institute of Child Health and Human Development (NICHD) Maternal-Fetal Medicine Units Network (MFMU), Eunice Kennedy Shriver NICHD Maternal-Fetal Medicine Units Network. Timing of elective repeat cesarean delivery at term and neonatal outcomes. N Engl J Med. 2009; 360(2): 111-120, doi: 10.1056/NEJMoa0803267, indexed in Pubmed: 19129525.

18. Segal S, Gemer O, Zohav E, et al. Evaluation of breast stimulation for induction of labor in women with a prior cesarean section and in grandmultiparas. Acta Obstet Gynecol Scand. 1995; 74(1): 40-41, doi: 10.3109/00016349509009941, indexed in Pubmed: 7856430.
19. Udayasankar V, Padmagirison R, Majoko F. National survey of obstetricians in Wales regarding induction of labour in women with a previous caesarean section. J Obstet Gynaecol. 2008; 28(1): 48-50, doi: 10.1080/01443610701812090, indexed in Pubmed: 18259898.

20. Tucker JM, Hauth JC, Hodgkins P, et al. Trial of labor after a one- or two-layer closure of a low transverse uterine incision. Am J Obstet Gynecol. 1993; 168(2): 545-546, doi: 10.1016/0002-9378(93)90490-a, indexed in Pubmed: 8438925.

21. Bujold E, Mehta SH, Bujold C, et al. The impact of a single-layer or double-layer closure on uterine rupture. Am J Obstet Gynecol. 2002; 186(6): 1326-1330, doi: 10.1067/mob.2002.122416, indexed in Pubmed: 12066117. 